\title{
Improving bovine udder health: A national mastitis control program in the Netherlands
}

\author{
T. J. G. M. Lam, ${ }^{*} \dagger \ddagger^{1}$ B. H. P. van den Borne, $† \S ~ J . ~ J a n s e n, \#$ K. Huijps,II J. C. L. van Veersen, ${ }^{*} \dagger$ \\ G. van Schaik, $†$ and H. Hogeveen $¥$ T \\ *UGCN, Dutch Udder Health Centre, PO Box 2030, 7420 AA Deventer, the Netherlands \\ †GD Animal Health Service, PO Box 9, 7400 AA Deventer, the Netherlands \\ fUtrecht University, Department Farm Animal Health, PO Box 80151, 3508 TD Utrecht, the Netherlands \\ $\S$ Veterinary Public Health Institute, Vetsuisse Faculty, University of Bern, Schwarzenburgstrasse 155, 3097 Bern, Switzerland \\ \#Wageningen UR, Livestock Research, PO Box 65, 8200 AB Lelystad, the Netherlands \\ IICRV, PO Box 454, 6800 AA Arnhem, the Netherlands \\ TWageningen University, Chair Group Business Economics, PO Box 8130, 6700 EW Wageningen, the Netherlands
}

\section{ABSTRACT}

Because of increasing bulk milk somatic cell counts and continuous clinical mastitis problems in a substantial number of herds, a national mastitis control program was started in 2005 to improve udder health in the Netherlands. The program started with founding the Dutch Udder Health Centre (UGCN), which had the task to coordinate the program. The program consisted of 2 parts: a research part and a knowledge-transfer part, which were integrated as much as possible. The knowledge-transfer part comprised 2 communication strategies: a central and a peripheral approach. The central approach was based on educating farmers using comprehensive science-based and rational argumentation about mastitis prevention and included on-farm study group meetings. Comprehensive education materials were developed for farmers that were internally motivated to improve udder health. In the peripheral approach it was tried to motivate farmers to implement certain management measures using nontechnical arguments. Mass media campaigns were used that focused on one single aspect of mastitis prevention. These communication strategies, as well as an integrated approach between various stakeholders and different scientific disciplines were used to reach as many farmers as possible. It should be noted that, because this intervention took place at a national level, no control group was available, as it would be impossible to isolate farmers from all forms of communication for 5 years. Based on several studies executed during and after the program, however, the results suggest that udder health seemed to have improved on a national level during the course of the program from 2005 to 2010 . Within a cohort of

Received July 18, 2012.

Accepted October 22, 2012.

${ }^{1}$ Corresponding author: t.lam@gddeventer.com dairy herds monitored during the program, the prevalence of subclinical mastitis did not change significantly (23.0 in 2004 vs. 22.2 in 2009). The incidence rate of clinical mastitis, however, decreased significantly, from 33.5 to 28.1 quarter cases per 100 cow years at risk. The most important elements of the farmers' mindset toward mastitis control also changed favorably. The simulated costs of mastitis per farm were reduced compared with a situation in which the mastitis would not have changed, with $€ 400$ per year. When this amount is extrapolated to all Dutch farms, the sector as a whole reduced the total costs of mastitis by $€ 8$ million per year. It is difficult to assign the improved udder health completely to the efforts of the program due to the lack of a control group. Nevertheless, investing $€ 8$ million by the Dutch dairy industry in a 5-yr national mastitis control program likely improved udder health and seemed to pay for itself financially.

Key words: national program, communication, extension, economics

\section{INTRODUCTION}

Mastitis impairs milk quality (Barbano et al., 2006), cow welfare (Kemp et al., 2008), leads to an increased risk of antibiotic residues (van Schaik et al., 2002), is very annoying for farmers whose working routine is disturbed (Jansen, 2010), may have a negative effect on the image of the dairy industry, and has monetary effects (Hogeveen et al., 2011). Recent estimates of the average economic losses caused by mastitis in different countries range from $€ 61$ to $€ 97$ per average cow in the herd (Hogeveen et al., 2011). However, large differences exist between farms within a country. In the Netherlands, the estimated total failure costs of mastitis varied from $€ 17$ to $€ 198$ per cow per year (Huijps et al., 2008). From the 1970s to 2000, bulk milk SCC (BMSCC) in the Netherlands steadily decreased (Sol, 
2002). This improvement stagnated in the beginning of this century, with increasing BMSCC levels and higher peaks in the summer periods. Additionally, field reports indicated that a substantial number of herds were experiencing problems with clinical mastitis (CM).

With that background, the Dutch dairy industry decided in 2004 to invest approximately €8 million levy money in a 5-yr national mastitis control program, with the ambitious goal of decreasing the incidence rate of clinical mastitis (IRCM) by 10 percentage points (van der Zwaag et al., 2005). The national mastitis control program was run by the Dutch Udder Health Centre (UGCN), which was especially founded to implement this control program. The UGCN served as an independent source of information on udder health for farmers and others, and initiated and coordinated research in a wide range of Dutch research institutes.

To prevent mastitis, one should consistently put effort in optimizing nutrition, host resistance, environmental conditions, milking equipment, milking technique, and hygiene (Bradley, 2002; LeBlanc et al., 2006). Additionally, proper data handling and goal setting are crucial to evaluate the measures taken. Many quantitative studies have demonstrated the effect of farm management practices on mastitis (e.g., Barkema et al., 1999; Barnouin et al., 2004; Green et al., 2007). Nevertheless, quantifiable management factors cannot explain the variance in mastitis incidence on farms completely. Differences in productivity between dairies have been described in spite of these farms having the same facilities, feed, genetic base, and environmental circumstances, the main difference between them being the herd manager (Seabrook, 1984). The same is likely the case for mastitis. Therefore, in the Dutch mastitis control program, besides knowledge transfer on optimal farm management practices, much attention was paid to change the attitude and behavior of farmers and veterinarians.

In many countries national mastitis control programs exist, varying from very applied such as the Australian Countdown Downunder project (Brightling et al., 2009) to more research oriented such as the Canadian Bovine Mastitis Research Network (Reyher et al., 2011). Several states in the United States have or had their programs (i.e., Reneau, 2007; Ruegg and Rodrigues, 2007) and especially Nordic countries have a long background in an organized approach of udder health (Østerås and Sølverød, 2009). Apparent differences in udder health in different countries exist (IDF Standing Committee on Animal Health, 2001). Although the dairy industry in these countries differs in aspects such as production systems, market circumstances, climate, and legislation, it shows that room for improvement exists in many countries and that one can learn from others' expe- riences. The experience and results generated by the Dutch mastitis control program can help others in the dairy industry worldwide improve or design their own mastitis control programs. The objective of this paper was to describe and evaluate the Dutch national mastitis control program with respect to mastitis occurrence, farmers' mindset and behavior, and farm economics.

\section{MATERIALS AND METHODS}

\section{The Dutch National Mastitis Control Program}

The national mastitis control program consisted of 2 parts: (1) initiating applied research and (2) transferring existing and new knowledge to the field. By having these 2 parts, research and practice were integrated. Approximately half of the available financial resources were invested in research projects that contributed to a substantial number of scientific publications and 9 $\mathrm{PhD}$ theses (Melchior, 2007; Hettinga, 2009; Halasa, 2009; Huijps, 2009; Sampimon, 2009; Bouwstra, 2010; Jansen, 2010; Ploegaert, 2010; van den Borne, 2010). All research activities were directed toward implementation into the field because they were paid by the dairy industry and, directly or indirectly, dairy farmers had to profit from the results. The other half of the resources was invested in knowledge transfer to dairy farmers and their advisors. Although the power of policy instruments such as regulations, BMSCC threshold levels, and bonuses on milk quality is known (e.g., Leeuwis, 2004; Nightingale et al., 2008), changing regulations was beyond the reach of the UGCN, who could not enforce changes in milk quality regulations. Thus, other strategies such as communication campaigns were used to enhance farmers' behavior to improve udder health in the Netherlands. The theoretical background of that approach has been described before (Jansen et al., 2010a; Lam et al., 2011; Jansen and Lam, 2012) and comprised 2 main communication strategies.

The first strategy, called the central approach (Jansen et al., 2010a), included on-farm study group meetings and the development of comprehensive education materials for farmers who were interested in participating in a program to improve udder health management. This strategy focused on improving udder health by educating farmers using comprehensive science-based and rational argumentation about mastitis prevention and treatment. In a survey conducted before the start of the program, farmers identified their veterinarian as the first person to approach when having udder health problems (Jansen et al., 2009). Therefore, the backbone of this type of knowledge transfer was formed by veterinary practitioners acting as intermediaries between the UGCN and farmers. In 2005, the approach and the 
material were developed in cooperation with 10 private veterinary practices (Lam et al., 2011). This was expanded to 50 practices in 2006 , and subsequently to as many practices as possible in 2007 and subsequent years. Ready-to-use packages were available for veterinarians, with information, score cards, and presentations to organize on-farm study group meetings with their dairy clients, but also to use in their daily practice work. Udder health topics were divided into 5 main themes: infection pressure, host resistance, treatment, milking, and control. These were also the themes of the study group meetings. Of the approximately 300 veterinary cattle practices in the Netherlands, over 200 participated in the program, serving approximately $85 \%$ of the Dutch dairy farms. Of the farmers served by the participating veterinary practices, 3,169 farmers (approximately 19\% of Dutch dairy farmers) participated in the on-farm study groups organized by the local veterinary practice. Participants were educated by their veterinarian on teat health, feed rations, milking machines, hygiene scores, and other relevant topics. An overview of all practical tools developed to be used in the central approach is presented in Table 1.

The second strategy was the peripheral approach. Here the UGCN tried to motivate farmers using nontechnical arguments to implement a certain management measure (Lam et al., 2011; Jansen and Lam, 2012). Mass media campaigns were used, that focused on one single aspect of mastitis prevention. Campaigns were organized on the use of milking gloves, timely replacement of teat cup liners, use of a white board for communication with and between milkers in the milking parlor, and use of a treatment protocol for antibiotics. In each of the campaigns, relevant stakeholders were involved, such as suppliers of agricultural products or pharmaceutical companies (Jansen et al., 2010a). These campaigns aimed at changing farmers' behavior through peripheral cues (Petty and Cacioppo, 1986). Attention was raised by formally launching the campaign during a specific kick-off meeting, articles in the agricultural press, and humorous postcards send to farmers or through the internet. Subsequently, individual farmers were visited as much as possible by suppliers (e.g., agricultural suppliers and veterinarians) of the involved product and free samples or discounts were offered. More details on, for example, the milking glove campaign have been described before (Jansen et al., 2010a).

Additionally, other communication strategies were used to reach as many farmers as possible using articles in various media, websites, newsletters, organization of workshops, specific meetings for robotic milkers, open farm days, symposia, udder health awards for excellent udder health achievements, and the development of a practical guide on first-rate udder health (Hulsen and Lam, 2007).

Some of the practical tools that were developed for the study groups in the central approach were also used in the peripheral approach, but without using much rational argumentation to encourage their use. Where the central approach basically focused on internally motivated farmers, the peripheral approach was not focusing on a specific group of farmers, but tried to reach as many farmers as possible, by cooperation with partners in the field and using a mix of communication styles (Jansen and Lam, 2012).

Table 1. Overview of the practical tools used in the central approach in the national mastitis control program in the Netherlands from 2005 to 2010

\begin{tabular}{ll}
\hline Theme & Tool \\
\hline Treatment & Treatment protocol for clinical mastitis \\
& Illustrated fact sheet on the California Mastitis Test (CMT) \\
& Illustrated fact sheet on milk sampling technique for bacteriology \\
& Illustrated fact sheet on injection technique in dairy cows \\
& Clinical mastitis treatment evaluation \\
& Dry cow treatment evaluation \\
& Resistance assessment - summary questionnaire \\
& Resistance assessment - detailed questionnaire \\
Host resistance & Practical guide to first-rate udder health \\
Control & Udder health assessment questionnaire \\
& Mastitis Cost Calculator (software) \\
& Mastitis monitor (software) \\
& Treatment protocol for subclinical mastitis \\
& Hygiene score assessment form \\
Infection pressure & Illustrated fact sheet on milking procedures and teat condition \\
Milking & Teat condition assessment form \\
& White board for communication in milking parlor \\
& The Milking Mirror (self-evaluation computer test) \\
&
\end{tabular}




\section{Study Design}

It should be noticed that, because this intervention took place at national level, no control group was possible. It is virtually impossible to isolate a control group of farmers from all forms of communication on udder health for $5 \mathrm{yr}$. Therefore, the effectiveness of the Dutch mastitis control program was evaluated based on data collected in 2 surveys in the same group of herds. The first survey was executed in the year before the national control program was launched. An observational survey was conducted from July 1, 2004, to June 30, 2005, in 396 randomly selected Dutch dairy herds (the 2004 survey). Details of this study are described elsewhere (Jansen et al., 2009; van den Borne et al., 2010). Herds had to participate in the 4 -weekly milk production recording (MPR) program; needed to have, on average, at least 50 dairy cows in the year 2003; and the farmer had to be younger than 57 years. These inclusion criteria were designed in such a way that it was likely that the farm would still be in operation in 2009. The MPR records of these 396 herds were obtained from the Dutch Cattle Syndicate (CRV BV, Arnhem, the Netherlands). From the herds in the 2004 survey, 205 herds eventually collected complete data on CM (van den Borne et al., 2010). No specific attention was given to the herds participating in the 2004 survey and, hence, the approach of these herds was the same as to other Dutch dairy herds during the UGCN mastitis control program. Five years later, 378 of the 396 herds in the 2004 survey were still in operation and were asked to participate in a second, identical survey from January 1, 2009, to December 31, 2009 (the 2009 survey). Of the 378 approached farmers, 266 were willing to participate again and MPR records were obtained from these farms. Reasons for farmers not to participate in the 2009 survey were described elsewhere (Jansen et al., 2010b). The nonresponders did not differ significantly from the responders with regard to their annual BMSCC in 2004 (Jansen et al., 2010b). Clinical mastitis records in the 2009 survey were eventually obtained from 175 dairy herds, of which 116 also participated in the 2004 CM survey.

\section{Evaluation of Mastitis Occurrence}

Herd level prevalence of subclinical mastitis (SCM) was defined as the average annual proportion of cows with a composite $\mathrm{SCC} \geq 200,000$ cells $/ \mathrm{mL}$. Herd-level prevalence of SCM in each survey was estimated using negative binomial models with a first-order autoregressive correlation structure to correct for monthly composite SCC measurements within herds. A combination of a sine-cosine function was added to correct for seasonal fluctuation. The model was fitted to the data of each survey separately and was as follows (van den Borne et al., 2010):

$$
\begin{aligned}
& \ln \mathrm{E}\left(\mathrm{Y}_{\mathrm{i}}\right)=\alpha+\beta \times \cos (2 \times \mathrm{m} / 12) \\
& +\beta \times \sin (2 \times \mathrm{m} / 12)+\ln \left(\mathrm{n}_{\mathrm{i}}\right)+\varepsilon_{\mathrm{i}},
\end{aligned}
$$

where $\ln E\left(Y_{i}\right)=$ natural logarithm of the expected number of cows with composite SCC $\geq 200,000$ cells/ $\mathrm{mL}$ at test day $\mathrm{i}, \alpha=$ intercept, $\beta=$ estimated regression parameter, $\mathrm{m}=$ month of MPR recording ( 1 to 12), $\ln \left(\mathrm{n}_{\mathrm{i}}\right)=$ natural logarithm of the total number of cows at risk at test day $\mathrm{i}$ as offset, and $\varepsilon_{\mathrm{i}}=$ residual error term. Prevalence of SCM and its 95\% confidence interval was estimated as $\mathrm{e}^{\alpha} \times 100 \%$ and represents the average within-herd proportion of cows with a composite $\mathrm{SCC} \geq 200,000$ cells $/ \mathrm{mL}$ in each survey.

A CM case was defined as a cow with visual abnormalities of the milk or quarter, or both. Clinical mastitis cases occurring within 2 wk of a previous case in the same quarter were excluded from the analysis. Cow days at risk were calculated as the total number of days a cow was present in the herd during the study. Herd-level IRCM was estimated for each survey separately using negative binomial models, as follows (van den Borne et al., 2010):

$$
\ln \mathrm{E}(\mathrm{Y})=\alpha+\ln (\text { dar })+\varepsilon,
$$

where $\ln \mathrm{E}(\mathrm{Y})=$ natural logarithm of the expected number of $\mathrm{CM}$ cases, $\alpha=$ intercept, $\ln ($ dar $)=$ natural logarithm of the total number of cow-days at risk as offset, and $\varepsilon=$ residual error term. Incidence rate of CM was expressed as the number of quarter clinical cases per 100 cow-years at risk and was estimated as $\mathrm{e}^{\alpha}$ $\times 365 \times 100$.

The calculated SCM prevalence and IRCM of herds that participated in both surveys were compared with estimates from herds that participated in only 1 survey. An extra variable describing the participation in the number of surveys ( 1 vs. 2 ) was added to the above described models for this purpose. Also, the data from both surveys were merged to determine the difference in prevalence of SCM and in IRCM over the course of the program. A variable describing the year of the survey (2004 vs. 2009) was added to determine whether the change was significant. In this case, the model for prevalence of SCM was adapted to correct for repeated test-day recordings within survey within herds and the model for IRCM was adjusted for repeated surveys within herds. First-order autoregressive correlation structures were added to these latter models. Signifi- 
cance was defined at the $P<0.05$ level. Model fit was determined as previously described (van den Borne et al., 2010) and all models showed a good fit. All analyses were performed using PROC GENMOD in SAS 9.2 (SAS Institute, Cary, NC).

\section{Evaluation of Knowledge, Attitude, and Behavior}

An extensive questionnaire on farmers' knowledge, attitude, and behavior was conducted at the start of both surveys to obtain information about farmers' mindset in the Netherlands (Jansen et al., 2009, 2010b). A team of veterinarians, farmers, animal health experts, communication experts, and social psychologists developed this questionnaire, containing 50 items regarding behavior and farm demographics, and 76 items about farmers' attitudes, knowledge, and information sources. Insights about farmers' self-reported behavior regarding mastitis were obtained by asking about actual activities, such as "Do you clean the teats before milking?" or "How often do you clean the cubicles?" Variables describing farmers' knowledge, attitude, and behavior were binary coded or on a 5-point Likert score in both surveys, according to how much farmers agreed or disagreed with the statements (Jansen et al., 2009; 2010b). For each survey variable, gain scores were calculated by subtracting the value in 2004 from the value in 2009. A positive gain score means an increased score on that question. Wilcoxon signed-rank tests $(P$ $\leq 0.05$ ) were performed to determine whether the gain scores deviated significantly from zero.

\section{Evaluation of Economics}

An estimation of the costs of mastitis for the entire Dutch dairy sector was made using a Monte Carlo simulation model at the herd level, simulating all Dutch dairy farms in 2004 and in 2009. Costs of CM were based on the estimated IRCM during the years 2004 and 2009. For each case of CM, milk production losses were assumed and multiplied by the value of milk production losses. Moreover, costs of treatment of the CM case were determined, consisting of antibiotics, discarded milk, veterinary assistance, and labor of the farmer. Finally a probability of culling was used multiplied by the costs of a culled cow (retention pay-off). Calculations were made as described by Huijps et al. (2008). Cost factors were normative (Table 2) and were chosen in such a way that they resembled the Dutch farming and market situation in 2004 and 2009. Differences between 2004 and 2009 cost factors were only taken into account when clear evidence existed of a change in price level. This meant that only price and market differences between 2004 and 2009 were taken into account because no insight was available into possible changes in factors such as production losses, culling, or veterinary visits due to changes in type of CM.

Input data with regard to farm numbers and milk production were based on national statistical databases. The number of dairy farms in the Netherlands in 2004 and 2009 was 24,319 and 20,268, respectively. The number of cows per farm was based on categorized data from the Dutch Central Bureau of Statistics (http://www.cbs.nl). For a simulated farm, the farm size category was simulated using a discrete distribution. Within each farm size category exact farm sizes were assumed to be uniformly distributed. A milk production level for each farm was selected using a normal distribution fitted on the Dutch milk production level in 2004 and 2009. Input with regard to BMSCC in 2004 was based on data from the milk quality control station (Qlip, Zutphen, the Netherlands). Because no statistical difference in BMSCC was found between 2004 and 2009 (Jansen et al., 2010b), BMSCC in 2009

Table 2. Assumptions used to calculate the costs of mastitis during the 2004 and 2009 surveys in the Netherlands

\begin{tabular}{lrc}
\hline Item & 2004 & 2009 \\
\hline Market and price assumptions & & \\
Costs of milk production losses $(€ / \mathrm{kg}$ of milk) & 0.12 & 0.13 \\
Costs of discarded milk $(€ / \mathrm{kg}$ milk) & 0.17 & 0.18 \\
Costs of antibiotics for treatment $(€ /$ treatment) & 33 & 35 \\
Costs of veterinary visits (€/visit) & 24 & 26 \\
Costs of labor ( $€ / \mathrm{h})$ & 20 & 20 \\
Costs of culled cows ( $€ /$ cow) & 480 & 480 \\
Costs per case of clinical mastitis $(€ /$ case) & 180 & 208 \\
Assumptions on clinical mastitis & & \\
Milk production losses (\% of 305-d milk production) & 5 & 5 \\
Duration of treatment (d) & 3 & 3 \\
Duration of additional withdrawal time (d) & 3 & 3 \\
Labor treatment (min) & 45 & 45 \\
Veterinary visits (\% of clinical mastitis cases) & 5 & 5 \\
Culling (\% of clinical cases) & 15 & 15 \\
\hline
\end{tabular}


was assumed to be equal to 2004. A distribution of IRCM (cases per average cow per year) was fitted for 4 BMSCC groups: BMSCC $<150,000$ cells $/ \mathrm{mL}$, BMSCC $\geq 150,000$ and $<250,000$ cells $/ \mathrm{mL}$, BMSCC $\geq 250,000$ and $<400,000$ cells $/ \mathrm{mL}$, and BMSCC $\geq 400,000$ cells/ $\mathrm{mL}$, for both 2004 and 2009. The IRCM was categorized into 4 categories; 0.02 to $0.10,0.10$ to $0.20,0.20$ to 0.40 , and 0.40 to 0.90 . In a similar way as for farm size, a combination of a discrete distribution to determine the IRCM category and of a uniform distribution to determine the exact IRCM within a category was used to simulate the IRCM for each individual farm.

Given the simulated farm size, milk production level, and mastitis situation, the costs for CM and SCM were calculated according to the method described by Huijps et al. (2008). Comparable to Huijps et al. (2008), the costs of SCM were based on the average yearly BMSCC, using estimations of the production losses due to an increased SCC under Dutch conditions, as described by Halasa (2009). Calculated costs for CM and SCM were summed to generate an estimation of the total failure costs for mastitis per farm.

In this simulation, the costs for mastitis in the years 2004 and 2009 were based on costs from individual farms, but were calculated for the entire Dutch dairy sector. Additionally, a 2009 situation was simulated, where the farm and market circumstances of 2009 were combined with the mastitis situation as in 2004. This was done to be able to estimate the net effect of the mastitis control program. In other words, what would likely have been the economic costs of mastitis in 2009 if the mastitis situation would not have changed?

\section{RESULTS}

\section{Herds}

In the 2004 survey, MPR data of 45,322 cows in 396 herds were available for analysis of prevalence of SCM, and from 35,099 cows in 266 dairy herds in 2009. The yearly average number of lactating cows per herd was $67.7(\mathrm{SD}=21.8)$ in 2004 and $80.3(\mathrm{SD}=29.9)$ in 2009. The average milk production was $26.8 \mathrm{~kg} / \mathrm{d}$ in 2004 and $27.1 \mathrm{~kg} / \mathrm{d}$ in 2009 . The average parity of lactating cows was 2.7, both in 2004 and 2009. The proportion of farms in the surveys with an automatic milking system increased from $0.5 \%$ in 2004 to $8.6 \%$ in 2009 . The number of full-time employees per farm hardly changed, being 1.7 in 2004 and 1.6 in 2009.

\section{Mastitis Occurrence}

Occurrences of CM and SCM in the Netherlands, according to the 2004 and the 2009 survey, are presented in Table 3. The IRCM decreased over the course of the 5 -yr mastitis control program. Mean herd-level IRCM was estimated to be 33.5 (cases per 100 cow-years at risk) in 2004, whereas it was significantly lower at 28.1 in $2009(P=0.002)$. The 2004 IRCM did not differ between herds that participated in both surveys $(\mathrm{n}=$ 116) and herds that participated in the 2004 survey only ( $\mathrm{n}=89 ; P=0.94$ ). The 2009 IRCM in herds that participated in both surveys $(\mathrm{n}=116)$ was higher compared with herds for which only reliable $\mathrm{CM}$ data for 2009 were available $(\mathrm{n}=59 ; P<0.001)$. The 2009 IRCM was 30.9 (95\% CI: 28.0-34.2) per 100 cow-years at risk for herds that participated in both surveys, whereas it was 22.5 (95\% CI: 19.2-26.4) for herds that only participated in the 2009 survey.

Although the prevalence of SCM in 2009 was lower than it was in 2004 (Table 3), this difference was statistically not significant $(P=0.20)$. The 2004 prevalence of SCM of herds that participated in both surveys (n $=266$ ) did not significantly differ from herds that only participated in the 2004 survey $(\mathrm{n}=130 ; P=0.29)$.

\section{Knowledge, Attitude, and Behavior}

Aspects of farmers' knowledge, attitude, and behavior changed significantly over the course of the mastitis control program. In the 2009 survey, farmers perceived that they had more knowledge about controlling mastitis problems than in 2004, and they stated more often that they knew the causes when a mastitis problem occurred [25\% (2004) vs. 37\% (2009)]. Extra work was more often perceived as the most annoying aspect of mastitis ( $26 \%$ vs. $49 \%$ ), and more farmers stated that

Table 3. Number of herds (n) and estimated average occurrence of clinical and subclinical mastitis (with $95 \%$ CI) in 2 surveys conducted in the Netherlands

\begin{tabular}{lcccccc}
\hline & \multicolumn{3}{c}{ Subclinical mastitis } & & \multicolumn{3}{c}{ Clinical mastitis } & \\
\cline { 2 - 3 } \cline { 5 - 6 } Year & $\mathrm{n}$ & Prevalence $^{1}$ & & $\mathrm{n}$ & Incidence rate $^{2}$ & Reference \\
\hline 2004 & 396 & $23.0(22.2-23.9)$ & & 205 & $33.5(31.3-35.8)$ & van den Borne et al. $(2010)$ \\
2009 & 266 & $22.2(21.4-23.2)$ & & 175 & $28.1(25.7-30.7)$ & This paper \\
\hline
\end{tabular}

${ }^{1}$ Proportion of cows with a composite SCC $\geq 200,000$ cells $/ \mathrm{mL}$.

${ }^{2}$ Number of quarter clinical mastitis cases per 100 cow-years at risk. 
Table 4. Results of an economic simulation for mastitis costs for the Dutch dairy sector in 2004 and 2009, with minimum and maximum values (in parentheses)

\begin{tabular}{|c|c|c|c|}
\hline Item $^{1}$ & 2004 & 2009 & 2009 (unchanged) \\
\hline \multicolumn{4}{|l|}{ Performance } \\
\hline Herd size (cows) & $67(15-158)$ & $80(18-181)$ & $80(18-181)^{2}$ \\
\hline Milk production (kg/cow per day) & $21(16-26)$ & $23(17-28)$ & $23(17-28)^{2}$ \\
\hline BMSCC $(\times 1,000$ cells $/ \mathrm{mL})$ & $216(119-336)$ & $216(119-336)$ & $216(119-336)^{4}$ \\
\hline \multicolumn{4}{|l|}{ Economics $(€ /$ cow per year $)$} \\
\hline Clinical mastitis & $61(20-115)$ & $60(14-134)$ & $64(21-121)$ \\
\hline Economics $(€ /$ farm per year $)$ & $4,862(892-12,041)$ & $5,825(949-15,369)$ & $6,231(1,116-15,484)$ \\
\hline Economics $(\times$ million $€ / \mathrm{yr})$ & 118.3 & 118.0 & 126.3 \\
\hline
\end{tabular}

it was important to keep the farm management simple (79 vs. 88\%). With regard to farmers' norms, their problem level of BMSCC changed; farmers perceived a problem at 285,000 cells $/ \mathrm{mL}$ in 2004 , compared with 271,000 cells/mL in 2009.

With regard to farmers' behavior, farmers more often took udder health characteristics into account when selecting bulls (46 vs. $61 \%$ ). The use of milking gloves increased from 15 to $46 \%$, the use of a herd-specific mastitis treatment protocol increased from 7 to $34 \%$, and cubicles were more often cleaned (2.28 vs. 2.51 times/d). More farmers used blanket antibiotic dry-cow therapy ( 85 vs. $94 \%$ ). More details on the changes in knowledge, attitude, and behavior between the start and the end of the national mastitis control program have been described before (Jansen et al., 2010b).

\section{Economics}

Economic results from the simulation for the entire Dutch dairy sector are presented in Table 4 . The average herd size and the milk production per cow per day increased from 2004 to 2009. The IRCM, presented as quarter cases per 100 cows per year, decreased between 2004 and 2009. Because no significant change in BMSCC occurred from 2004 to 2009, the simulated BMSCC levels were equal for 2004 and 2009. Despite the increased costs for milk production losses, antibiotics, and veterinary services (Table 2), the total costs for mastitis $(€ /$ cow per year) in 2009 was more or less the same as in 2004. Because of the increased farm size, the total costs per farm increased from $€ 4,862$ per farm in 2004 to $€ 5,825$ per farm in 2009 . The costs per case of CM increased from, on average, €180 in 2004 to €208 in 2009 (Table 2). The costs of mastitis for the entire Dutch dairy sector slightly decreased from 2004 to 2009
(€0.3 million). However, if the mastitis incidence would not have changed in 2009, and the 2004 IRCM data were used in the 2009 situation with regard to factors such as farm size, milk production, and prices, the situation would have been very different. In that simulation, the 2009 costs per farm and for the entire dairy sector would have been considerably higher (the column "2009 unchanged" in Table 4). The economic savings (actual costs compared with expected costs) due to the lower average IRCM is estimated to be approximately $€ 400$ per year per farm, and approximately $€ 8$ million per year for the entire Dutch dairy sector.

\section{DISCUSSION}

The aim of this paper was to describe and evaluate the effectiveness of the Dutch mastitis control program as it was executed by the UGCN from 2005 to 2010 . The basis for the evaluation were 2 surveys that were as identical as possible, and were held in the same herds. After the initial survey in 2004, these herds were not specifically informed on any of the aspects of the UGCN activities, because these activities were addressed as much as possible to all dairy farmers in the country. Veterinary practitioners who participated in the program were not informed about whether or not their clients participated in the 2004 study. In that sense, these farmers were considered as representative of Dutch dairy farmers. The aim was to include the same herds in both surveys to minimize bias caused by between-herd variability due to, for instance, CM diagnosis. However, not all herds participated in both surveys, which may have influenced the results. Some herds stopped their farming activities during the course of the program and some were no longer willing to collect data for the study. Others, however, who were un- 
able or unwilling to collect reliable CM data in 2004, did so in 2009. The surveys showed that the prevalence of SCM did not change significantly, whereas the IRCM decreased significantly. The occurrences of mastitis in the 2004 and 2009 surveys were compared between herds participating in both surveys and herds that participated in only one of them. In 2004, no difference existed in the prevalence of SCM and the IRCM between those herds. In 2009, however, the IRCM of herds participating in both surveys was 1.4-fold higher than of herds of which only $2009 \mathrm{CM}$ data were available. A possible explanation for this observation could be the knowledge transfer initiated by the program. During the 5 -yr mastitis control program farmers received a lot of information on, for example, the importance of early diagnosis of CM. This may have resulted in more farmers being willing to register CM data. It may also have led to improved and, therefore, increased CM detection in the 2009 survey. The latter would have resulted in an overreporting of the IRCM in 2009, implying that the observed decrease of IRCM may very well be an underestimation of the true effect.

Assuming that the herds in the survey are a good representation of all Dutch dairy herds, it remains difficult to truly evaluate the effectiveness of the mastitis control program and to assign the changes found solely to the intervention. Almost all dairy herds in the Netherlands were exposed to the activities of the program, either by the activities of a local practitioner, the mass-media approach, or through other sources. Although the survey results can be considered representative for the total effect of all activities, they cannot be compared with a control group of herds that were not exposed to the activities. Hence, the observed decrease in IRCM might be due to year-to-year variation in, for instance, temperature, quality of the feed, or culling policies due to different market circumstances. Nevertheless, as in other studies where it was not possible to create a representative control group (e.g., Rasmussen et al., 2002), there are reasons to believe that the estimates obtained from the surveys reflect an effect of the UGCN program. Although not much data are available to compare results, trends in other countries where no programs were started (yet) did not show an improvement in udder health (Piepers et al., 2011), whereas countries that did, showed a favorable effect, either at the level of participating herds (Green et al., 2007) or at the country level for national programs (Østerås and Sølverød, 2009). Also, the mindset of farmers toward udder health changed over the course of the program and over 3,000 farmers participated in study groups on the subject. These changes in farmers' mindsets were associated with changes in udder health (Jansen et al., 2010b; van den Borne et al., 2011). As was described in other countries (Green et al., 2007), it was also shown in a selected cohort of dairy herds that udder health improved in dairy herds that actively implemented the mastitis control program compared with herds that did not do so (Lam et al., 2011).

Our findings showed that, on top of measurable differences in mastitis management, a substantial part of the variance in IRCM can be explained by farmer mindset (Jansen et al., 2009). This is supported by studies of Bigras-Poulin et al. (1985) and Tarabla and Dodd (1990), who identified the effect of farmer mindset on farm performance. Thus, for a mastitis control program, it is important to pay attention to elements of farmer mindset to change farmers' management practices to improve udder health (Jansen and Lam, 2012). The 2004 survey showed that farmers perceived mastitis as an important problem: $92 \%$ of the farmers wanted to decrease mastitis on their farms, and no less than $79 \%$ of the farmers were interested in the prevention of mastitis. However, only $38 \%$ of the respondents thought that they should actually do more about mastitis prevention. Many dairy farmers either considered the mastitis problems not serious enough, or the offered solutions not effective enough (not efficacious or too difficult to implement) to come to action. These factors are also known to be indispensable in motivating people to work on their own health and are described in the so-called Health Belief Model (Janz and Becker, 1984). This model seems to apply to udder health management very well. If farmers think that their cows are not susceptible to IMI or think mastitis is not a severe animal health or economic problem, they will not be internally motivated to change their udder health management. Likewise, if required mastitis management measures are perceived as ineffective or difficult to implement, farmers will not be internally motivated to change their mastitis management (Garforth et al., 2006; Huijps et al., 2008). Thus, important elements of mastitis control programs to stimulate internal motivation to improve udder health are perceived impact of mastitis and perceived efficacy of management measures (Jansen and Lam, 2012).

With the central approach in which the importance of the problem is shown, as is the effect of the measures to be taken, one will not reach all farmers. To reach as many farmers as possible, the UGCN communication approach used various strategies, described as the central approach for internally motivated farmers and the peripheral approach for farmers who were less internally motivated. The traditional central route uses comprehensive, rational, science-based educational tools in, for example, study group settings and direct contacts between practitioners and farmers during herd health visits. Peripheral communication strategies, such as 
the milking glove campaign (Jansen et al., 2010a), can be quite effective in changing farmers' behavior. The results showed that not only the use of gloves changed, but also the opinion of farmers about the usefulness of wearing gloves, even though no rational arguments were used in the campaign. However, to be able to send a message via a peripheral approach, the sender has to be trusted by the receiver (Hansen et al., 2003). We tried to gain this trust from farmers by starting the program with the central approach during the first 2 yr of its existence. That, combined with starting to publish research results in both scientific and farmers' journals made the UGCN a well-known institute with authority in the mastitis field. The UGCN operated together with, but independent from, other stakeholders. A step-by-step approach was chosen, trying to change farmer behavior using central as well as peripheral communication strategies. By ongoing efforts of the mastitis control program, including the development of educational tools and the implementation of study groups, we tried to enhance farmers' motivation to work on udder health.

The calculated failure costs of mastitis, as presented in this paper, were in line with other recent Dutch estimations (Huijps et al., 2008; Halasa, 2009). Differences between farms in the current calculations were based on differences in $\mathrm{CM}$ and SCM and milk production level per cow per day. In reality, however, more factors change over the years, such as the risk of culling, the costs of culling, costs of treatment, and valuation of milk production losses (Huijps et al., 2008). All of these variables were fixed in the simulations because specific values for individual farms for each survey were not known. At the national level, the best available estimates of IRCM and BMSCC were used (Table 3). For this simulation, assuming the mastitis situation of 2004 for the 2009 farm and market circumstances gave the most realistic estimation of the economic effect of the UGCN program. The difference between the failure costs of mastitis in 2004 and 2009 was approximately $€ 8$ million per year. The costs of the UGCN program were approximately €1.6 million per year for a 5 -yr period. This indicates that the program was cost-effective, paying the total investment of the dairy industry back in $1 \mathrm{yr}$.

A large proportion of the economic losses was due to a decrease in milk production and an increase in discarded milk due to treatment. These were valued for a quota situation, where farmers deliver a fixed amount of milk. The economic consequences of milk production losses are, therefore, equal to the additional costs to have more cows to fill the milk quota $(€ 0.13$ per kilogram of milk in 2009). In 2015, the European Union milk quota system will be abandoned, implying that farmers do not have to deliver a fixed amount of milk. Milk production losses will then directly influence milk returns. Depending on price levels of milk and feed, it is expected that the costs of milk production losses will be $€ 0.25$ to $€ 0.30$ per kilogram of milk. This means that the costs of mastitis will approximately double. Given this change in valuation of milk production losses, mastitis control will become even more beneficial. This and other reasons, such as the increasing political pressure on antibiotic use, animal welfare, and environmental issues, make it important to continuously try to improve udder health, not only at the farm level to solve mastitis problems, but also at a regional or national level to try to improve the results of the entire dairy industry.

\section{CONCLUSIONS}

In a 5-yr mastitis control program in the Netherlands, technical information about best management practices was distributed to dairy farmers. Several communication strategies, as well as an integrated approach between various stakeholders and different scientific disciplines were used to reach as many farmers as possible. Although no control group existed because mastitis control was initiated at the national level, udder health seemed to have improved during the course of the program with a significant decrease in IRCM and an improved farmers' mindset toward mastitis control. The most important elements of the latter that changed were the awareness of the mastitis situation and the perceived efficacy of preventive measures. The simulated costs of mastitis per farm were reduced by approximately $6.5 \%$ compared with a situation in which the mastitis situation would not have changed. The difference between the failure costs of mastitis in 2004 and 2009 was approximately €8 million per year at the national level. The costs of the UGCN program were approximately €1.6 million per year for a 5 -yr period. This indicates that the program was likely to be cost-effective, paying the total investment of the dairy industry back in $1 \mathrm{yr}$. The results of this program may inspire other countries to invest in udder health, not only for economic reasons, but also for animal welfare, reduction of antibiotic resistance, and total image of the dairy industry.

\section{ACKNOWLEDGMENTS}

This paper presents the results of the 5-yr mastitis control program of the Dutch Udder Health Centre (UGCN, Deventer, the Netherlands), which was financially supported by the Dutch Dairy Board (PZ, Zoetermeer, the Netherlands) and initiated by the Agriculture and Horticulture Association (LTO, The 
Hague, the Netherlands) and the Dutch Dairy Association (NZO, Zoetermeer, the Netherlands). The authors gratefully acknowledge the efforts of all people involved in the program and the farmers who participated in this study. We also thank the Dutch Cattle Syndicate (CRV BV, Arnhem, the Netherlands) and the Milk Quality Control Station (Qlip, Zutphen, the Netherlands) for providing data. Writing of this paper was financially supported by the Netherlands Committee of the International Dairy Federation.

\section{REFERENCES}

Barbano, D. M., Y. Ma, and M. V. Santos. 2006. Influence of raw milk quality on fluid milk shelf life. J. Dairy Sci. 89(Suppl. 1):E15E19.

Barkema, H. W., Y. H. Schukken, T. J. G. M. Lam, M. L. Beiboer, G. Benedictus, and A. Brand. 1999. Management factors associated with the incidence rate of clinical mastitis. J. Dairy Sci. 82:1643-1654.

Barnouin, J., M. Chassagne, S. Bazin, and D. Boichard. 2004. Management practices from questionnaire surveys in herds with very low somatic cell score through a national mastitis program in France. J. Dairy Sci. 87:3989-3999.

Bigras-Poulin, M., A. H. Meek, S. W. Martin, and I. McMillan. 1985. Attitudes, management practices, and herd performance-A study of Ontario dairy farm managers. II. Associations. Prev. Vet. Med. $3: 241-250$.

Bouwstra, R. J. 2010. Mastitis and oxidative stress in vitamin E supplemented dairy cows. PhD Thesis. Utrecht University, Utrecht, the Netherlands.

Bradley, A. J. 2002. Bovine mastitis: An evolving disease. Vet. J. 164:116-128.

Brightling, P. B., R. D. Dyson, A. F. Hope, and J. Penry. 2009. A national programme for mastitis control in Australia: Countdown Downunder. Vet. J. 62(Suppl. 4):S52-S58.

Garforth, C., K. McKemey, T. Rehman, R. B. Tranter, R. J. Cooke, J. B. Park, P. T. Dorward, and C. M. Yates. 2006. Farmers' attitudes towards techniques for improving oestrus detection in dairy herds in South West England. Livest. Sci. 103:158-168.

Green, M. J., K. A. Leach, J. E. Breen, L. E. Green, and A. Bradley. 2007. National intervention study of mastitis control in dairy herds in England and Wales. Vet. Rec. 160:287-293.

Halasa, T. H. B. 2009. Bio-economic modeling of bovine intramammary infections. PhD Thesis. Utrecht University, Utrecht, the Netherlands.

Hansen, J., L. Holm, L. Frewer, P. Robinson, and P. Sandøe. 2003. Beyond the knowledge deficit: Recent research into lay and expert attitudes into food risks. Appetite 41:111-121.

Hettinga, K. A. 2009. Quality control of raw cows' milk by headspace analysis - A new approach to mastitis diagnosis. PhD Thesis. Wageningen University, Wageningen, the Netherlands.

Hogeveen, H., K. Huijps, and T. J. G. M. Lam. 2011. Motivating producers to improve udder health: Impact of economics. N. Z Vet. J. 59:16-23.

Huijps, K. 2009. Economic decisions in mastitis management. PhD Thesis. Utrecht University, Utrecht, the Netherlands.

Huijps, K., T. J. G. M. Lam, and H. Hogeveen. 2008. Costs of mastitis: Facts and perception. J. Dairy Res. 75:113-120.

Hulsen, J., and T. Lam. 2007. Udder Health: A Practical Guide to First-Rate Udder Health. Roodbont Publishers, Zutphen, the Netherlands.

IDF Standing Committee on Animal Health. 2001. Mastitis control in member countries. Pages 11-42 in Mastitis Newsletter 24. International Dairy Federation (IDF), Brussels, Belgium.

Jansen, J. 2010. Mastitis and farmer mindset. Towards effective communication strategies to improve udder health management on
Dutch dairy farms. PhD Thesis. Wageningen University, Wageningen, the Netherlands.

Jansen, J., and T. J. G. M. Lam. 2012. The role of communication in improving udder health. Vet. Clin. North Am. Food Anim. Pract. 28:363-379.

Jansen, J., R. J. Renes, and T. J. G. M. Lam. 2010a. Evaluation of two communication strategies to improve udder health management. J. Dairy Sci. 93:604-612.

Jansen, J., B. H. P. van den Borne, R. J. Renes, G. van Schaik, T. J. G. M. Lam, and C. Leeuwis. 2009. Explaining mastitis incidence in Dutch dairy farming: The influence of farmers' attitudes and behavior. Prev. Vet. Med. 92:210-223.

Jansen, J., G. van Schaik, R. J. Renes, and T. J. G. M. Lam. 2010b. The effect of a national mastitis control program on attitudes, knowledge, and behavior of farmers in the Netherlands. J. Dairy Sci. 93:5737-5747.

Janz, N. K., and M. H. Becker. 1984. The health belief model: A decade later. Health Educ. Q. 11:1-47.

Kemp, M. H., A. M. Nolan, P. J. Cripps, and J. L. Fitzpatrick. 2008. Animal-based measurements of the severity of mastitis in dairy cows. Vet. Rec. 163:175-179.

Lam, T. J. G. M., J. Jansen, B. H. P. van den Borne, R. J. Renes, and H. Hogeveen. 2011. What veterinarians need to know about communication to optimize their role as advisors on udder health in dairy herds. N. Z. Vet. J. 59:8-15.

LeBlanc, S. J., K. D. Lissemore, D. F. Kelton, T. F. Duffield, and K. E. Leslie. 2006. Major advances in disease prevention in dairy cattle. J. Dairy Sci. 89:1267-1279.

Leeuwis, C. 2004. Communication for rural innovation. Rethinking agricultural extension. 3rd ed. Blackwell Science Ltd., Oxford, UK.

Melchior, M. B. 2007. Biofilms: Implications for the therapy of bovine Staphylococcus aureus mastitis. $\mathrm{PhD}$ Thesis. Utrecht University, Utrecht, the Netherlands.

Nightingale, C., K. Dhuyvetter, R. Mitchell, and Y. H. Schukken 2008. Influence of variable milk quality premiums on observed milk quality. J. Dairy Sci. 91:1236-1244.

Østerås, O., and L. Sølverød. 2009. Norwegian mastitis control programme. Ir. Vet. J. 62(Suppl. 4):S26-S33.

Petty, R. E., and J. T. Cacioppo. 1986. The elaboration likelihood model of persuasion. Pages 123-205 in Advances in Experimental Social Psychology. L. Berkowitz, ed. Academic Press, New York, NY.

Piepers, S., K. Lommelen, J. De Meulemeester, and S. De Vliegher. 2011. 'Demo-project udder health': A first step towards a better udder health and milk quality in Flanders (Belgium). Pages 85-89 in Udder Health and Communication. H. Hogeveen, and T. J. G. M. Lam, ed. Wageningen Academic Publishers, Wageningen, the Netherlands.

Ploegaert, T. C. W. 2010. Parameters for natural resistance in bovine milk. PhD Thesis. Wageningen University, Wageningen, the Netherlands.

Rasmussen, M. D., M. Bjerring, P. Justesen, and L. Jepsen. 2002. Milk quality on Danish farms with automatic milking systems. J. Dairy Sci. 85:2869-2878

Reneau, J. K. 2007. Quality count\$: A SCC reducing campaign in Minnesota. Pages 136-141 in Proc. NMC, San Antonio TX. National Mastitis Council (NMC), Verona, WI.

Reyher, K. K., S. Dufour, H. W. Barkema, L. Des Côteaux, T. J. DeVries, I. R. Dohoo, G. P. Keefe, J. P. Roy, and D. T. Scholl. 2011. The National Cohort of Dairy Farms - A data collection platform for mastitis research in Canada. J. Dairy Sci. 94:1616-1626.

Ruegg, P., and A. C. Rodrigues. 2007. Implementing milk quality programs on farms: Lessons learned from 'milk money'. Pages 152 158 in Proc. NMC, San Antonio, TX. National Mastitis Council (NMC), Verona, WI

Sampimon, O. C. 2009. Coagulase-negative staphylococci mastitis in Dutch dairy herds. PhD Thesis. Utrecht University, Utrecht, the Netherlands.

Seabrook, M. F. 1984. The psychological interaction between the stockman and his animals and its influence on performance of pigs and dairy cows. Vet. Rec. 115:84-87. 
Sol, J. 2002. Cure of Staphylococcus aureus mastitis in Dutch dairy cows. PhD Thesis. Utrecht University, Utrecht, the Netherlands.

Tarabla, H. D., and K. Dodd. 1990. Associations between farmers' personal characteristics, management practices and farm performance. Br. Vet. J. 146:157-164.

van den Borne, B. H. P. 2010. Impact of bovine subclinical mastitis and effect of lactational treatment. PhD Thesis. Utrecht University, Utrecht, the Netherlands.

van den Borne, B. H. P., T. J. G. M. Lam, O. C. Sampimon, J. Jansen, and G. van Schaik. 2011. The effect of a national control program on mastitis occurrence in the Netherlands. Pages 101-108 in Udder Health and Communication. H. Hogeveen, and T. J. G. M. Lam, ed. Wageningen Academic Publishers, Wageningen, the Netherlands. van den Borne, B. H. P., G. van Schaik, T. J. G. M. Lam, and M. Nielen. 2010. Variation in herd level mastitis indicators between primiand multiparae in Dutch dairy herds. Prev. Vet. Med. 96:49-55.

van der Zwaag, H. G., G. van Schaik, and T. J. G. M. Lam. 2005. Mastitis control program in the Netherlands: Goal, tools and conditions. Pages 509-604 in Mastitis in dairy production-Current knowledge and future solutions. H. Hogeveen, ed. Wageningen Academic Publishers, Wageningen, the Netherlands.

van Schaik, G., M. Lotem, and Y. H. Schukken. 2002. Trends in somatic cell counts, bacterial counts, and antibiotic residue violations in New York State during 1999-2000. J. Dairy Sci. 85:782-789. 